\title{
Relación género/sexo y masculino inclusivo plural en español ${ }^{*}$
}

\section{Luis Barrera Linares ${ }^{* *}$}

\section{Resumen}

En este artículo se analizan dos temas: la vinculación semántica género/sexo y algunas de las alternativas emergentes para la sustitución del masculino plural inclusivo en español. Primero, se realiza un acercamiento a la normativa académica en relación con la formación del género gramatical. Luego, se abordan la creación de marcas morfológicas de lenguaje inclusivo y los resultados de una encuesta acerca del género y de la conciencia lingüística. Tercero, se muestran algunas opciones sustitutivas del masculino inclusivo y una serie de opiniones de hablantes públicos en torno al tópico. Finalmente, se discuten los pros y los contras para la utilización de la 'e' frente a otras alternativas sintagmáticas ya en uso. Las conclusiones destacan la conciencia lingüística de los hablantes respecto de la relación género/sexo y la mejor adecuación de algunas de las propuestas morfosintagmáticas para sustituir el masculino inclusivo.

Palabras clave: género, masculino inclusivo, propuestas léxicas y sintagmáticas.

\section{Gender/sex relationship and plural inclusive masculine in Spanish}

\begin{abstract}
This paper refers the gender/sex relationship, and some proposals related to inclusive language in plural formation of Spanish (pro)nouns. Firstly, Spanish gender rules are discussed. Secondly, it approaches problems associated to emerging Spanish morphological marks. Data from a survey about linguistic consciousness are shown. Thirdly, we summarize some academic opinions on these topics. The most important conclusions are: speakers undoubtedly have linguistic consciousness about both gender/sex relationship and the grammatical rule related to plural inclusive masculine in Spanish; some morpho-syntagmatic and lexical proposals could be more suitable than others regarding creation of a gender-neutral suffix such as 'e'.
\end{abstract}

Keywords: Spanish genre/sex, Plural masculine inclusive, Lexical and morpho-syntagmatic proposals.

\footnotetext{
* Una versión inicial de este trabajo fue presentada como ponencia durante el workshop sobre lenguaje inclusivo, realizado el 14 de mayo de 2019 en la Universidad Católica Silva Henríquez, UCSH. ** Venezolano. Doctor en Letras de la Universidad Simón Bolívar (Caracas) y Magíster en Lingüística Aplicada (Essex University, Inglaterra). Numerario de la Academia Venezolana de la Lengua, AVL y miembro correspondiente de la Real Academia Española, RAE. Integrante del equipo de Prácticas Lectoras y Escritura Académica (PLEAc), de la Universidad Católica Silva Henríquez, UCSH, Santiago, Chile.lbarrera@ucsh.cl. El autor agradece la lectura, comentarios y observaciones al original de parte de los colegas César Villegas, Lucía Fraca, Ricardo Sánchez Lara e Yraida Sánchez.
} 
Hay tres géneros, macho, hembra y neutro. Dionisio de Tracia (170 a.C-90 a.C.). Tékhnē Grammatikép

\section{El lenguaje inclusivo y sus aristas}

Individualidades, instituciones de diversa naturaleza y gobiernos de distinta orientación ideológica parecen haber asumido esta centuria como la apropiada para reforzar - con razón o sin ella-, algunas peticiones públicas relacionadas con cambios lingüísticos que, de antemano, presuponen como necesarios, casi siempre en pro de la igualdad o respeto de determinados grupos sociales ${ }^{2}$. Este tópico sobrepasa lo meramente léxico y desde hace algunos años viene asomando la posibilidad de adentrarse en lo sintáctico y en lo morfológico del sistema lingüístico (Acosta, 2016). En cuanto al vocabulario que alude a sustantivos femeninos, basta con prestar atención a cualquier medio o red social de la actualidad para leer o escuchar términos como *dirigenta, *idola, *miembra, *testiga, *cónsula, *jequesa $a^{3}$, entre otras ${ }^{4}$.

En esta misma orientación entraría la insistencia en las llamadas duplas sintagmáticas o léxicas que desde hace algún tiempo procuran diferenciar los referentes masculino y femenino mediante diversos procedimientos, tanto en la oralidad como en la lengua escrita. La idea según la cual ciertas expresiones del idioma son "sexistas" se ha implantado ya en nuestras sociedades iberoamericanas (Acosta, 2016; Cabeza Pereiro y Rodríguez Barcia, 2013; Ecker \& McConnel-Ginet, 2003; Llamas Sáiz, 2015; Márquez Guerrero, 2016) y no parece prudente argumentar de antemano que algunas son inviables porque auspician fenómenos imposibles de penetrar el sistema de la lengua (Álvarez de Miranda, 2012; Grijelmo, 2018; Moure, 2018; Rodríguez Ordóñez citado en Prieto, 2018). Por ejemplo, se hace complicado convencer a un hablante común de que no existe una relación de correspondencia entre el género gramatical y el sexo biológico, principalmente cuando

Traducción al español, comentada, de Bécares Botas (2002).

Es preciso aclarar, además, que como bien argumenta Kozac (2018), esto nada tiene que ver con ideologías de izquierdas o de derechas. Se trata de un asunto que es lingüístico y toca muy de cerca lo sociológico y lo político.

3 Vocablos precedidos de un asterisco son aquellos aún no incorporados al DLE como correspondientes femeninos de profesión u oficio. En tales casos, una sola posibilidad representa a ambas opciones (m. y f., género común).

4 Algunas de ellas ya localizables en el Corpus de Referencia del Español Actual (CREA), aunque con bajos niveles de frecuencia. 
se alude a las personas. A tal efecto Vigara Tauste (2008) señala: "Si hay algún ámbito en que los hablantes de español sintamos el deseo o la necesidad de 'hacer explícito el sexo del referente' ese es, sin duda, el de

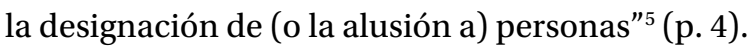

Dentro de la orientación que busca incidir en lo lingüístico para generar modificaciones, han cobrado mucha fuerza en los últimos tiempos las propuestas de carácter morfológico. Alternativas, por cierto, no carentes de limitaciones, por cuanto se trata del nivel de una lengua más difícil de modificar en el tiempo (García Mouton, 2012). Es natural que los inventarios morfosintácticos cerrados resulten más fuertes en cuanto a posibilidades de alteración, pero ello no significa que sean absolutamente imposibles de modificar (o evolucionar). También es verdad que quienes impulsan los cambios lingüísticos son los hablantes y, según la misma autora, entre la masa amorfa e indiferenciada de usuarios destaca especialmente el papel de las mujeres de clase media:

Los que ponen en marcha un cambio lingüístico que los demás hablantes aceptan y generalizan son los líderes lingüísticos que, en la mayor parte de los casos estudiados, se identifican con mujeres de clase media, no necesariamente jóvenes, cuyo ámbito de actuación no se limita a un puesto social determinado, sino que mantienen contacto en la escala social - hacia arriba y hacia abajo - con personas con las que no siempre coinciden en generación ni en clase social, y eso las convierte en excepcionales agentes de difusión del cambio (García Mouton, 2012, p. 69).

Además del rol que puedan desempeñar las mujeres en los cambios - asunto a nuestro juicio muy importante, debido a que buena parte de las actuales propuestas de modificación proceden precisamente de organizaciones feministas-, es evidente que ciertas iniciativas ganan más terreno del que esperarían algunos académicos y lingüistas. Ese será precisamente el tópico principal de este artículo: indagar acerca de las propuestas léxicas, morfológicas y morfosintagmáticas que buscan romper con la invisibilidad de lo femenino implícita en el uso de voces y expresiones referentes a lo que se conoce como masculino inclusivo no marcado.

\footnotetext{
Acerca de esta idea relacionada con la motivación del género puede verse también el trabajo de Cabeza Pereiro y Rodríguez Barcia (2013): “El carácter omnipresente de la categoría no excluye, sin embargo, que esté vivo en nuestra conciencia lingüística el recurso del género para señalar, cuando lo creemos preciso, si nos estamos refiriendo a mujeres o a hombres" (p. 11).
} 
Para ello, hemos dividido el desarrollo del documento en cuatro partes. Primero, se especifica lo que dicta la normativa académica acerca de la formación del género en español y sus vínculos con la relación género gramatical/sexo. Para esto servirá de base el manual de la Nueva gramática de la lengua española (en adelante NGLE, Real Academia Española, RAE-Asociación de Academias de la Lengua Española, ASALE, 2012). En segundo lugar, abordaremos la problemática relacionada con las opciones de una posible marca gramatical de lenguaje inclusivo no sexista (en adelante LI). Tercero, resumiremos algunas opiniones relevantes de hablantes públicos respecto de esa posibilidad. Entre los apartes primero y segundo, mostraremos los resultados de una encuesta ad hoc, realizada a propósito de la relación sexo/género gramatical y de la percepción real que tienen los hablantes en torno al masculino plural inclusivo. Desde una mirada que busca ser mediadora entre los puntos de vista extremistas acerca del LI, el objetivo general es aproximarnos de manera exploratoria a la posibilidad de una investigación más amplia, con base en tres premisas de trabajo:

a) Se hace difícil convencer al hablante común de la diferencia entre género gramatical y sexo biológico.

b) La noción del masculino como género inclusivo forma parte de la memoria semántica del colectivo hispanohablante.

c) Independientemente de su operatividad y/o posibilidad de éxito, entre las distintas propuestas de creación de una marca gramatical que sustituya al masculino inclusivo en español, la más razonable parece ser la que propone una 'e' como posibilidad. La meta final es investigar lo que ocurre con quienes realmente hacen uso del lenguaje para efectos prácticos de comunicación.

\section{Género: norma académica y relación con sexo biológico}

Si bien se suele afirmar que el género en español (y en otras lenguas romances) tiene base léxica y no morfológica - "no está motivado", afirma Rodríguez Díez (2005, p. 799) - y que parece servir solo para establecer las relaciones sintácticas de concordancia con determinantes y complementos o adjuntos ${ }^{6}$, eso puede valer como argumento para lingüistas o

6 “en la mayoría de los sustantivos del español y de las lenguas romances, el género es fijo y no supone o añade información semántica (...) Esto explica que fundamentalmente el valor del género resida en 
profesores de lengua, pero no para una masa de hablantes a la cual, por lo general, le interesa mucho más producir o interpretar mensajes en contexto, en lugar de discutir sobre asuntos técnicos propios del metalenguaje. No hay rasgos morfológicos de género explícitos en los sustantivos cuyos referentes son seres +animados y +sexuados, pero tampoco hay modo de que, aun aislados, los usuarios no los piensen y procesen como masculinos o femeninos (motivación implícita o motivación pragmática, como señala Márquez, 2013). He ahí la primera razón para que se piense que la marca del femenino y la "no marca" del masculino sean asuntos que sobrepasan lo estrictamente gramatical y académico, para ubicarse en lo contextual y, por ende, en lo sociológico y/o sociopolítico (Cabeza Pereiro y Rodríguez Barcia, 2013).

Asumiendo una posición conciliadora, diríamos que se trata de un asunto más sicosociolingüístico y pragmático que morfosintáctico. La intuición lingüística hace pensar al hablante común que sí existe un vínculo; se trata de una creencia apoyada en antiguas convicciones. Como hemos visto en el epígrafe, viene de la tradición griega y, posiblemente, de ahí pasó a la latina. Para el caso del español, aparece ya instaurada, por ejemplo, en la primera Gramática Castellana de Antonio de Nebrija (1492): “Género en el nombre es aquello por que el macho se distingue de la hembra, i el neutro de entrambos" (citado en Roca, p. 54); y reiterada en otras gramáticas posteriores, incluidas las versiones anteriores de la RAE, como señala Hernández García-Cervigón (2006):

En la edición de 1874, bajo la influencia de la Gramática General, a través de V. Salvá y A. Bello, se explica que, al tener primacía las personas entre todos los seres y objetos en que puede fijarse la atención del hombre, e inmediatamente después los animales, se distinguieron dos géneros por el sexo, el masculino y el femenino ${ }^{7}$ (p. 314).

\footnotetext{
ser mera valencia combinatoria, en ser soporte formal de la concordancia: en tener, en suma, un valor gramatical" (Rodríguez Díez, 2005, p. 799). Hay que añadir que no faltan quienes difieren de esta creencia acerca de la no motivación del género en español. Un exhaustivo y muy amplio recuento de esto último puede leerse en Márquez (2013, cap. 2) y en Cabeza Pereiro y Rodríguez Barcia (2013).

Véase específicamente lo que dice Bello (1847): “160 (86). Para determinar el género de los sustantivos debe atenderse ya al significado ya a la terminación. (87). Por razón del significado son masculinos: 161. 1.0 Los sustantivos que significan varón o macho o seres que nos representamos como de este sexo, verbigracia: Dios, ángel, duende, hombre, patriarca, tetrarca, monarca, león, centauro, Calígula, Rocinante, Babieca" (p. 83). "Por razón del significado son femeninos: 164. 1.0 Los sustantivos que nos representamos como mujer o hembra, o seres que nos representamos como de este sexo, verbigracia, diosa, ninfa, hada, leona, Zafo, Juno, Dulcinea, Zapaquilda” (p. 84).
} 
Esta concepción se mantiene incluso hasta la edición de la Gramática de la RAE (1931), que tuvo vigencia durante más de 42 años desde su publicación hasta 1973, cuando aparece la versión conocida como Esbozo de una nueva gramática de la lengua española, que no era propiamente una gramática en el pleno sentido sino, como su título lo indica, una especie de ensayo y antecedente para la actual, la NGLE, cuya primera edición es de 2009. Ya en el Esbozo... aparecía la aclaratoria: "Por el género, los sustantivos en español se dividen en masculinos y femeninos. La categoría nominal del neutro no existe en la lengua española" (1973, p. 172). No obstante, esto solo alude a la posibilidad de un morfema específico porque, en cuanto a lo semántico, más adelante expresa:

2.2.4. Significación del género de los nombres de persona. - Si los nombres sustantivos apelativos son de persona, tenemos la idea de que femeninos y masculinos, tal como acabamos de definirlos, designan respectivamente mujer y varón, o hembra y macho de algunas especies animales. Esta idea se acerca bastante a la verdad (RAE, p. $174^{8}$ ).

Así, al menos desde Antonio de Nebrija (1492) — por no decir desde la antigüedad grecolatina-, durante mucho tiempo se debe haber estado repitiendo esta vinculación género/sexo en la escuela, en los manuales, en libros de texto, en las instituciones, y en multitud de documentos de distinta naturaleza.

El mismo Esbozo... (RAE, 1973) incluye una nota a pie de página en la que nos recuerda que “Con el término 'genos' se designa en griego tanto el término gramatical como el sexo de los seres vivos" (p. 172, nota 6). Esta idea ha quedado fijada en la cultura de muchas generaciones y evidencia que no sea nada sencillo obviarla ahora como verdad, debido a que forma parte de lo que en términos morinianos se denomina imaginario colectivo o, en los estudios sobre cognición, de la memoria semántica (en este caso, del mundo hispanohablante). Citando a Cole (1999), Cabeza Pereiro y Rodríguez Barcia (2013) hablan de "esquemas culturales compartidos intersubjetivamente" (p. 9).

Aunque cualquier gramática de este tiempo insiste en justificar la improcedencia de la relación género/sexo, ni siquiera en trabajos bastante recientes se ignora esto como una tendencia difícil de erradicar:

Subrayados añadidos. 
"en el caso de las palabras que designan seres sexuados, como por ejemplo chico/a, lo normal es que el género lleve asociado un valor semántico de sexo" (Borrego Nieto, 2013, p. 252) ${ }^{9}$.

A fin de explorar la situación con hablantes reales, concretos, ajenos al metalenguaje de la teoría gramatical, diseñamos, validamos y aplicamos una encuesta escrita, constituida por dos partes: una relacionada con la asociación género/sexo y otra, con el plural masculino inclusivo. Se trata de un instrumento de tipo descriptivo, cerrado, con opción de respuesta dicotómica (Sí/No), validada mediante una prueba piloto con seis profesionales universitarios, hablantes nativos de español hispanoamericano, no docentes.

El instrumento fue suministrado posteriormente a un grupo de 40 informantes de características similares, incluidos en cuatro rangos de edad (25-34 años; 35-44 años; 45-54 años; más de 55 años), a razón de cinco mujeres y cinco hombres por cada rango ${ }^{10}$.

La primera parte de la encuesta buscaba verificar, sobre la base de cuatro preguntas muy específicas, cómo conciben los encuestados la relación género/sexo. Para ello, se les formularon los siguientes requerimientos:

1. ¿Crees que en español palabras como niño y niña se refieren al sexo masculino y femenino respectivamente?

2. ¿Consideras que la palabra perro remite a 'perro macho' y la palabra gata se refiere solo a 'gata hembra'?

3. ¿Hombre es a varón como mujer es a hembra?

4. La maestra dice: "Los niños que se quieran apuntar al tenis que levanten la mano". ¿Se ha dirigido a niños y niñas?

La segunda parte del instrumento incluyó una serie de requerimientos cuya interrogante fue la siguiente:

1. ¿Crees que en las siguientes expresiones como (la palabra subrayada) se incluye igual a hombres y mujeres?

\footnotetext{
$9 \quad$ En un interesante y muy explicativo trabajo, García Meseguer (2001) hace un esfuerzo notable para demostrar la improcedencia de ambos conceptos (género gramatical/sexo biológico) y ofrece múltiples ejemplos para ratificarlo, mas no deja de reconocer el peso de la tradición en este asunto: “Aunque indemostrable, no es arriesgado suponer que quien bautizó por primera vez a los géneros gramaticales con los adjetivos 'masculino' y ‘femenino', lo hizo así pensando que el primero era propio del varón y el segundo de la mujer” (p. 30).

10 La idea de focalizarnos en profesionales universitarios de varios grupos etarios obedece a la intención de consultar a hablantes que teóricamente se desenvuelven dentro de los parámetros de lo que se conoce como lengua estándar: desde algunos muy jóvenes (25-35 años), todavía marcados por su cercanía con la escolaridad formal, hasta otros pertenecientes a grupos mayores ( +55 años).
} 
Luego de la pregunta aparecía una serie de 10 oraciones relacionadas con el masculino plural inclusivo, cada una compuesta por los sustantivos: sobrecargos, modelos, náufragos, conserjes, jueces, compadres, astronautas, monarcas, viajeros, personajes (por ejemplo: "Esta semana habrá huelga de sobrecargos", "Hay personas a quienes no quisiera como compadres", "Los personajes deambulaban como fantasmas por el escenario", etc.) ${ }^{11}$.

Los resultados porcentuales de la primera parte aparecen especificados en la Tabla 1 y hablan por sí solos. El límite para las respuestas positivas superó el $75 \%$, con una sola excepción: el grupo de 45-54 años femenino alcanzó 68,7\%. Hubo incluso dos casos curiosos dentro del rango +55 años: aunque la encuesta era cerrada, dos de los informantes (residentes en distintos países, una venezolana y un chileno) se permitieron anotar sendas aclaratorias que ratificaban aún más la relación semántica género/sexo. Al margen del texto correspondiente a las dos primeras preguntas, aclararon (subrayados añadidos):

Inf. $3 \mathrm{M}+55$

Ítem 1. "Niños en plural se puede usar para referirse a los dos sexos".

Ítem 2. "Perros en plural se puede usar para referirse a los dos sexos".

Inf. $5 \mathrm{~F}+55$

Ítem 1. "Yo agregara (sic) que si digo los niños, ahí cabe (sic) los sexos masculino y femenino".

Ítem 4. "La pregunta de la maestra me causó duda, porque no sabía si era maestra de niños del sexo masculino o mixta”.

Incluso, dada su particular connotación sociológica, la denominación 'hembra' se utilizó muy a propósito para ver si generaba alguna duda, pero ello no ocurrió: salvo el grupo de 45-54 años masculino -entre quienes el No alcanzó un $100 \%$ - en el resto de los rangos etarios, el porcentaje menor del Sí fue de $60 \%$, en tanto el promedio general llegó a $64,9 \%$. Los resultados de la encuesta abren una muy importante posibilidad para investigar con mayor profundidad respecto de este tópico: por mucho que insista la gramática, en el caso de seres animados, la gente suele asociar género gramatical con sexo, hecho que confirmaría la premisa a) Se hace difícil convencer al hablante común de la diferencia entre género gramatical y sexo biológico.

\footnotetext{
11 Originalmente pensamos en incluir también otras preguntas relacionadas con vocablos de género común (por ejemplo, cónyuge) y epiceno (víctima) pero, por sugerencias de varios colegas, finalmente decidimos obviarlos pensando en otra futura encuesta que considere las diferencias de percepción relacionadas con estos aspectos.
} 


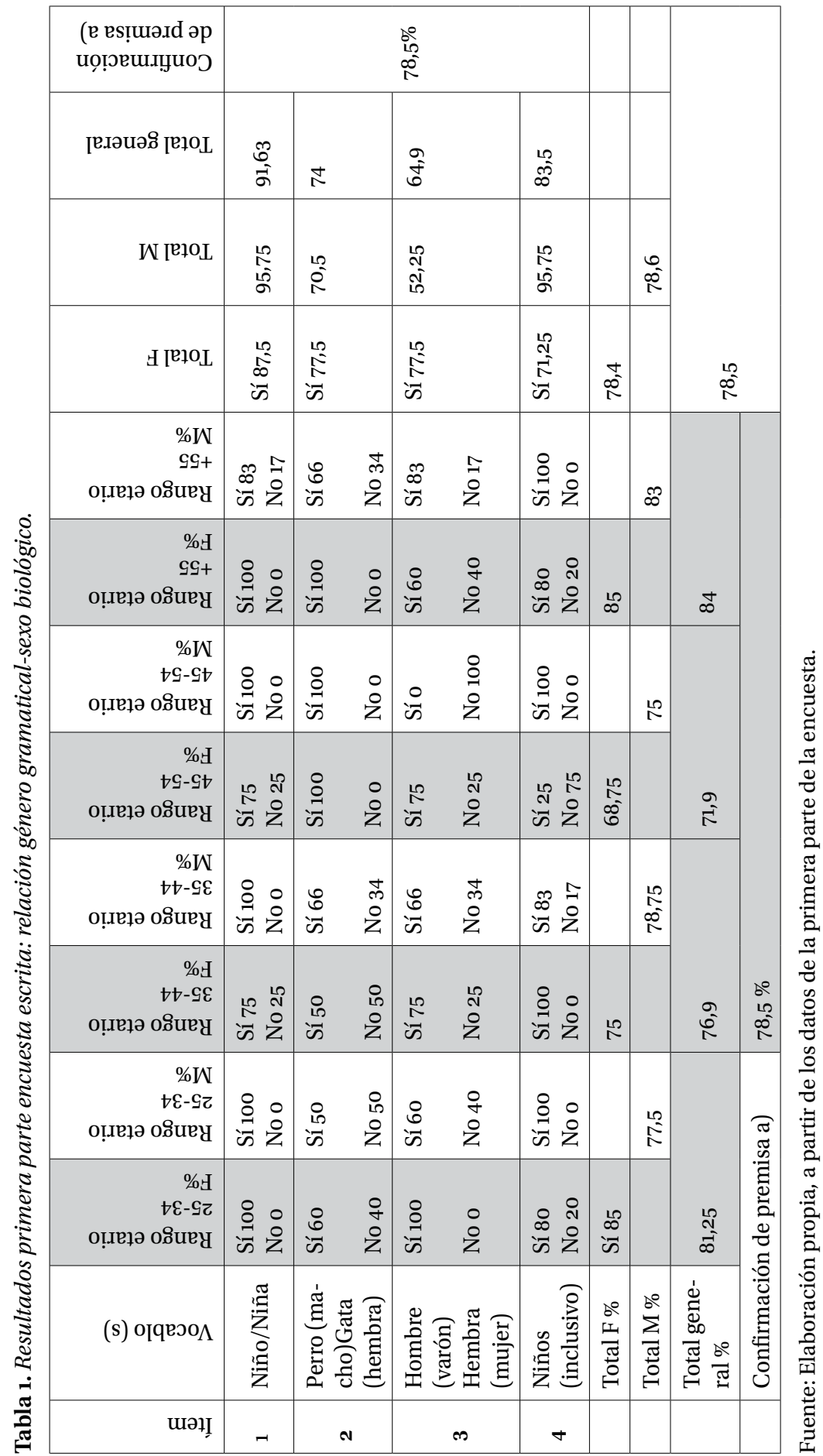


Para el caso niño/a, los hombres encuestados parecieron tener más certeza que las mujeres acerca de la asociación con el sexo. En cambio, en cuanto a animales, fueron las mujeres que respondieron la encuesta quienes más vincularon semánticamente la dupla género/sexo. No obstante, en general, la relación es mayor cuando se trata de seres humanos y menor con los animales. En cuanto a los nexos hombre/varón y mujer/hembra, pareciera que no se entendió bien lo que buscábamos, o bien, lo planteamos de manera ambigua y pudo haber sido asociado con la primera acepción de 'hembra' que ofrece el DLE ("animal del sexo femenino"), cuyo significado acarrea repercusiones sociológicas peyorativas. Debido a esto, el ítem no ha resultado confiable y tendríamos que obviarlo. Respecto de niños, las mujeres encuestadas lo consideraron menos inclusivo que los hombres pero, en general, los datos muestran que el término es incluyente para todos.

Ahora bien, no parecen existir diferencias notorias entre unos grupos y otros. Los de 25-34 años y los de +55 años mostraron inclinaciones similares. La mayoría de ellos coincidió en la asociación género/sexo y reconoció el uso del masculino plural inclusivo (más o menos en promedio general de un 78,5\%). Por su parte, los grupos intermedios (35-44 años y 45-54 años) parecen menos conservadores (76,9\% y 71,9\% respectivamente), lo que podría implicar que a la larga se consustancien mejor con el lenguaje no sexista. El mayor conservatismo de los grupos extremos podría asociarse con que los participantes de 25-34 años tienen menos tiempo de haber dejado las aulas universitarias y la escuela (a veces bastante conservadora, al menos en Hispanoamérica) y eso pudiera haber influido en sus concepciones. Los de +55 años tienen ya una valoración establecida, firme, y serían los más reacios a modificar a futuro sus convicciones.

\section{El masculino plural inclusivo}

Aunque en verdad son pocos, hay casos de vocablos en los cuales se haría dudosa la posibilidad genérica inclusiva, por cuanto parecieran solo aludir al masculino; ¿qué pensaríamos, por ejemplo, de una oración como “Los sobrecargos son profesionales de la aviación?”: ¿Incluiríamos en esa expresión a las damas que también ejecutan ese oficio? Lo mismo podríamos preguntarnos de "Los conserjes no suscribieron el comunicado, los modelos no acudieron a la pasarela, los náufragos fueron rescatados 
sanos y salvos". Si bien sobrecargos, conserjes, modelos y náufragos abren la posibilidad de ser considerados inclusivos desde el punto de vista gramatical, podríamos intentar un ejercicio mediante el cual verifiquemos esto en la realidad del lenguaje cotidiano. Lo mismo valdría para otros términos como jueces, compadres, cónyuges, astronautas, monarcas, viajeros, personajes, etc. ${ }^{12}$. En tal sentido, la Tabla 2 recoge los porcentajes de respuestas obtenidos en la segunda parte de la encuesta.

Aunque exploratorios, los resultados globales ratifican el reconocimiento casi total del plural masculino como inclusivo (premisa b). Entre los casos en que no se obtuvo el cien por ciento resaltaron, en primer lugar, el término compadres, hecho que ocurrió en casi todos los grupos; solo un 77,6\% lo considera inclusivo. Posiblemente esto obedezca a la relación con los heterónimos originales (padre/madre) y con el suyo propio, comadres. Los otros son sobrecargos (84,4\%, en general, y $75 \%$ para el grupo masculino), conserjes $(83,5 \%$, en general, y $71,25 \%$ para el grupo femenino) y monarcas $(89,1 \%$, en general, y $82,5 \%$ entre las mujeres). En términos globales, el resto supera el $94 \%$ para ambos sexos.

12 Por tratarse de una propuesta preliminar, la mayoría de los vocablos incluidos en ambas partes de la encuesta fueron seleccionados al azar, luego de haber realizado un inventario de todos los ejemplos contemplados en las referencias de este artículo. 


\begin{tabular}{|c|c|c|c|c|c|c|c|c|c|c|c|c|c|c|}
\hline 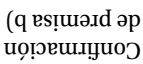 & \multicolumn{10}{|c|}{5} & & & \multirow[b]{4}{*}{ תָ } & \\
\hline 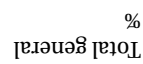 & $\frac{d}{8}$ & 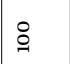 & ò & $\begin{array}{l}12 \\
\infty \\
\infty\end{array}$ & 竎 & 足 & 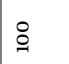 & $\widehat{D}$ & @ & oे & & & & \\
\hline$\% \mathrm{~N} \mathrm{IE \nmid OL}$ & $\stackrel{R}{1}$ & 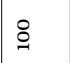 & 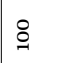 & 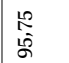 & 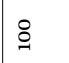 & $\begin{array}{ll}4 \\
2 \\
15 \\
\infty \\
\infty\end{array}$ & 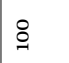 & 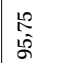 & $@$ & 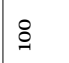 & & \& & & \\
\hline \% & 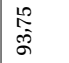 & 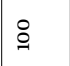 & $\begin{array}{l}\stackrel{1}{2} \\
2 \\
\Omega\end{array}$ & $\underset{\substack{n \\
N \\
N}}{R}$ & $\begin{array}{l}\stackrel{2}{1} \\
0 \\
\infty \\
\infty\end{array}$ & $\stackrel{i}{i}$ & 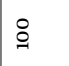 & 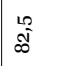 & $\cong$ & 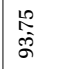 & $\begin{array}{l}2 \\
2 \\
5 \\
5\end{array}$ & & & \\
\hline 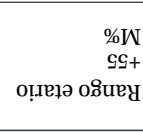 & 莺 & 㝵 & 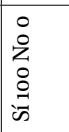 & 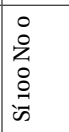 & 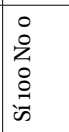 & 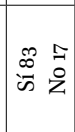 & 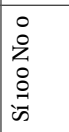 & $\begin{array}{l}\circ \\
\vdots \\
\vdots \\
\vdots \\
\vdots \\
\vdots\end{array}$ & \begin{tabular}{l}
$\circ$ \\
$\vdots$ \\
$\vdots$ \\
$\vdots$ \\
\hdashline
\end{tabular} & 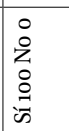 & & $\begin{array}{c}2 \\
\infty^{2}\end{array}$ & & \\
\hline 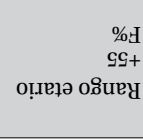 & 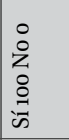 & \begin{tabular}{l}
$\circ$ \\
$\vdots$ \\
$\vdots$ \\
$\vdots$ \\
\hdashline \\
$\ddot{\infty}$
\end{tabular} & $\begin{array}{l}0 \\
\vdots \\
z \\
\vdots \\
\vdots \\
\ddot{\infty}\end{array}$ & $\begin{array}{l}0 \\
\vdots \\
\vdots \\
\vdots \\
\vdots \\
\dot{0}\end{array}$ & $\begin{array}{l}0 \\
\vdots \\
\vdots \\
\vdots \\
\vdots \\
\dot{0}\end{array}$ & 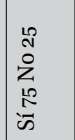 & \begin{tabular}{l}
0 \\
$\vdots$ \\
$z$ \\
$\vdots$ \\
$\vdots$ \\
\hdashline \\
$\dot{0}$
\end{tabular} & \begin{tabular}{l}
$\circ$ \\
$\vdots$ \\
$\vdots$ \\
$\vdots$ \\
\hdashline \\
\hdashline
\end{tabular} & $\begin{array}{l}0 \\
\vdots \\
\vdots \\
\vdots \\
\vdots \\
i n\end{array}$ & $\begin{array}{l}0 \\
\vdots \\
\vdots \\
\vdots \\
\vdots \\
i n\end{array}$ & \begin{tabular}{|c|}
10 \\
5 \\
5
\end{tabular} & & ڤે & \\
\hline 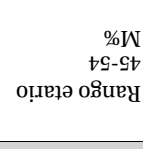 & $\begin{array}{ll} & 8 \\
0 & 0 \\
i n & z \\
1\end{array}$ & 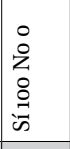 & $\begin{array}{l}0 \\
\vdots \\
\vdots \\
o \\
\vdots \\
\vdots \\
0\end{array}$ & 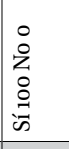 & \begin{tabular}{l}
0 \\
$\vdots$ \\
$\vdots$ \\
$\vdots$ \\
\hdashline \\
\hdashline
\end{tabular} & $\begin{array}{l}0 \\
\vdots \\
\vdots \\
\vdots \\
\vdots \\
\vdots\end{array}$ & 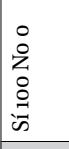 & $\begin{array}{l}\circ \\
\vdots \\
\vdots \\
\vdots \\
\vdots\end{array}$ & \begin{tabular}{l}
0 \\
$\vdots$ \\
$\vdots$ \\
\hdashline \\
\hdashline \\
\hdashline
\end{tabular} & 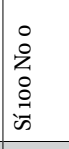 & & $\begin{array}{l}0 \\
\vdots \\
\end{array}$ & & \\
\hline 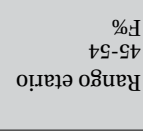 & $\begin{array}{ll}10 & 10 \\
& 0 \\
i & 2\end{array}$ & 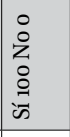 & 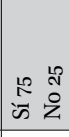 & 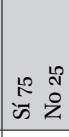 & 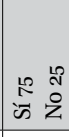 & \begin{tabular}{ll}
10 & \multicolumn{2}{c}{} \\
& 0 \\
2 & $z$
\end{tabular} & 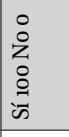 & 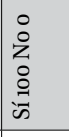 & \begin{tabular}{l}
0 \\
$\vdots$ \\
$\vdots$ \\
$\vdots$ \\
\hdashline \\
$i n$
\end{tabular} & 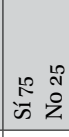 & \begin{tabular}{|c|}
0 \\
10 \\
$\infty$ \\
$\infty$
\end{tabular} & & $\underset{\substack{10 \\
\infty}}{\infty}$ & 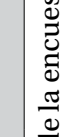 \\
\hline 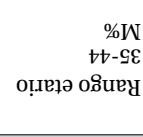 & 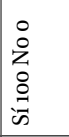 & 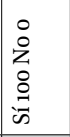 & $\begin{array}{l}\circ \\
\vdots \\
\vdots \\
\vdots \\
\vdots \\
\vdots\end{array}$ & $\begin{array}{ll}\infty & 5 \\
\infty & 0 \\
i & z\end{array}$ & 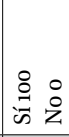 & 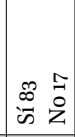 & $\begin{array}{l}0 \\
\vdots \\
\vdots \\
\vdots \\
\vdots \\
0\end{array}$ & \begin{tabular}{ll}
$\infty$ & \multicolumn{1}{c}{} \\
$\infty$ & 0 \\
$i$ & $z$
\end{tabular} & $\begin{array}{l}0 \\
\vdots \\
\vdots \\
\vdots \\
\vdots \\
i n\end{array}$ & \begin{tabular}{l}
$\circ$ \\
$\vdots$ \\
$\vdots$ \\
$\vdots$ \\
$\vdots$ \\
\hdashline
\end{tabular} & & $\stackrel{q}{\dot{\sigma}}$ & & 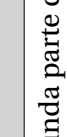 \\
\hline 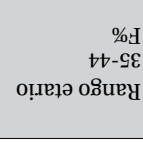 & $\begin{array}{l}0 \\
\vdots \\
z \\
\vdots \\
o \\
\vdots \\
\vdots \\
\end{array}$ & \begin{tabular}{l}
0 \\
$\vdots$ \\
$\vdots$ \\
$\vdots$ \\
\hdashline \\
$\ddot{n}$
\end{tabular} & \begin{tabular}{l}
0 \\
$\vdots$ \\
$\vdots$ \\
$\vdots$ \\
\hdashline \\
\hdashline
\end{tabular} & 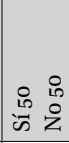 & $\begin{array}{l}0 \\
\vdots \\
z \\
\vdots \\
\vdots \\
i\end{array}$ & $\begin{array}{ll}0 & 0 \\
i n & 0 \\
i n & z\end{array}$ & 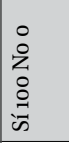 & 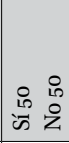 & $\begin{array}{l}0 \\
\vdots \\
\vdots \\
\vdots \\
0\end{array}$ & 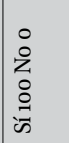 & \begin{tabular}{c|c}
0 \\
$i \hat{0}$ \\
$\infty$
\end{tabular} & & \begin{tabular}{c|c}
$\qquad$ & 0 \\
$\vdots$ & $\vdots$ \\
$\infty$ & $\vdots$
\end{tabular} & 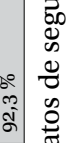 \\
\hline 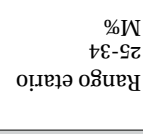 & $\begin{array}{ll}0 & 0 \\
\omega & z\end{array}$ & 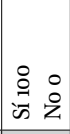 & 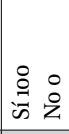 & 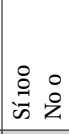 & 总 。 & 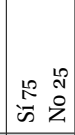 & 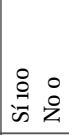 & 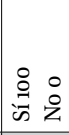 & 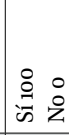 & 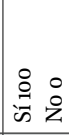 & & 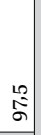 & & : \\
\hline 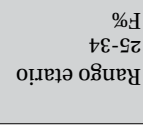 & \begin{tabular}{l}
$\circ$ \\
\hdashline \\
$i$
\end{tabular} & 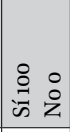 & 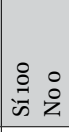 & $\begin{array}{ll}8 & 9 \\
i & 0 \\
i & z\end{array}$ & 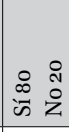 & 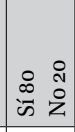 & 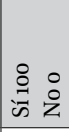 & 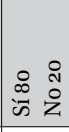 & \begin{tabular}{ll}
$\stackrel{0}{\circ}$ \\
\hdashline
\end{tabular} & 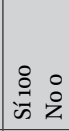 & $\begin{array}{l}0 \\
\vdots \\
\vdots\end{array}$ & & 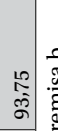 & 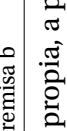 \\
\hline отqв оо & 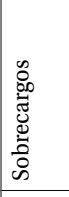 & $\frac{0}{0}$ & 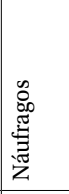 & 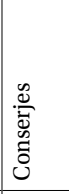 & 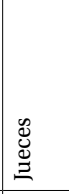 & 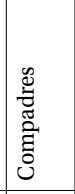 & 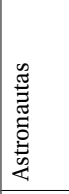 & 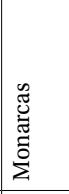 & 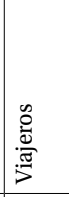 & 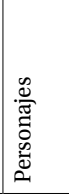 & 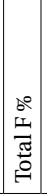 & 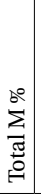 & 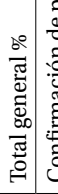 & 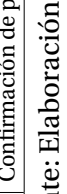 \\
\hline шәџ! & - & N & m & $\theta$ & in & 0 & N & $\infty$ & $a$ & 9 & & & & 这 \\
\hline
\end{tabular}


En cuanto a modelos, astronautas y viajeros, parece no haber ninguna duda de parte de los informantes. Sus respuestas indican que los perciben como inclusivos. Posiblemente tenga que ver con la dificultad y/o resistencia para pensar en formas como 'astronauto' y 'modela'. Eso explicaría ambas opciones, pero no se compaginaría con la tercera, porque 'viajera' es de uso común desde hace mucho tiempo. Sobrecargos, náufragos y personajes, en tanto, tampoco ofrecen problemas, salvo para el grupo 45-54 años. Es decir, las respuestas obtenidas muestran mayoritariamente el uso del masculino plural inclusivo, con pequeñas diferencias: conserjes solo es completamente aceptado por el grupo +55 años; por jueces tienen obvia preferencia los grupos 35-44 años y +55 años. Pero en todos los casos, los de mayor edad resultan siempre los más conservadores respecto del masculino plural inclusivo. Monarcas se percibe inestable entre los grupos más jóvenes (25-34 años, 35-44 años). Los más apegados a la inclusividad del masculino son 25-34 años y +54 años ( $i$ conservadores por las mismas razones esgrimidas cuando habláramos de los resultados sobre sexo/género?). Finalmente, los hombres encuestados aparecen como más partidarios del uso tradicional que las mujeres (gestoras de cambio, como decíamos arriba). De nuevo, los grupos más propensos al cambio parecen ser los intermedios (35-44 años, 45-54 años).

En suma, los resultados que aparentan salirse de la respuesta más general no son significativos frente a la mayoría que, a grandes rasgos, ha confirmado como inclusivos la mayoría de los ejemplos contenidos en la segunda parte de la encuesta. Posiblemente en esto incida el mismo fenómeno con que explicáramos la relación género/sexo: el uso recurrente del masculino plural inclusivo, su enseñanza en todos los niveles escolares (incluido el universitario) durante muchos años, la presencia en diversos documentos de todo tipo, lo han consagrado como parte de la competencia sicosociocomunicativa de los hablantes. Con esto se confirma que una cosa es lo que piensan quienes promueven aquellas propuestas o alternativas (léxicas, sintagmáticas o morfológicas) que eliminen la invisibilidad del femenino en los términos inclusivos y otra muy distinta la competencia concreta, realista, de los hablantes. Sin embargo, tampoco eso invalida la posibilidad de algún cambio futuro. Solo indica que, si bien determinadas opciones lucen más razonables que otras - como veremos más adelante-, la modificación del sistema lingüístico para lograrlas no es tan sencilla como pareciera (Cabeza 
Pereiro y Rodríguez Barcia, 2013) y necesariamente habría que insertarlas en el uso dentro de todas las esferas comunicativas, lo cual toma su tiempo.

\section{Alternativas que buscan hacer visible lo invisibilizado}

Se sabe que el inventario de una lengua está en constantes movimientos que cada cierto tiempo originan innovaciones. Para referirse al vocabulario que, por diversos motivos, se va extinguiendo López Morales (1988) y García Mouton (2012) hablan, por ejemplo, de muerte o mortandad léxica, respectivamente, esto es, mientras unas palabras desaparecen, muchas otras van surgiendo cada día, pero tal vez el concepto de mortandad no resulte siempre adecuado, ya que existe vocabulario que permanece latente dentro de ciertos formatos populares (canciones, himnos, refranes y dichos, por ejemplo) y los hablantes lo repiten sin conocer su significado, como parte de un ritual, pero sin que pueda considerarse vocabulario pasivo. Barrera Linares (2013) lo llama léxico hibernante, esto es, que en algún momento podría reaparecer en el discurso cotidiano. En todo caso, el subsistema lexical está en permanente renovación y es el más vulnerable. Esto podría ser una ventaja para las opciones léxicas y morfosintagmáticas dirigidas a buscar una solución al problema del LI a través de dicho subcomponente. De allí que sean hasta ahora las más recomendadas y utilizadas en su documentación oficial por diversas instituciones.

En cuanto a otros subsistemas, como el fonológico y el morfosintáctico, el asunto es algo más complicado, o más lento, ya que a veces los cambios implican largos períodos de tiempo, incluso siglos. Lo que sí es cierto es que ningún cambio lingüístico ocurre por “decreto" o por la voluntad expresa de un hablante, un grupo de ellos o una institución. Toda modificación del sistema está sujeta al consenso social, lo que implica que es el uso recurrente el que va marcando los pasos de cualquier transformación. Sin embargo, tampoco las obras que recogen la reglamentación lingüística de una determinada época son de carácter permanente. Ya lo decía Andrés Bello (1847, p. 421): “Las gramáticas y diccionarios exponen el uso de la gente culta y letrada, y sus decisiones no pueden ser por tanto definitivas". En consecuencia, más lenta o más rápidamente, los sistemas lingüísticos son siempre susceptibles al cambio. Tratándose de usos (y aunque algunos académicos, docentes o lingüistas lo consideren improcedente o imposible), tal vez desde la 
masa de hablantes puedan impulsarse innovaciones, principalmente si se propician dentro de las esferas del habla pública y la educación.

El tema no es solo del español, ni se trata de un tópico nuevo ni original. Lo que ocurre es que en nuestra lengua su discusión se ha recrudecido y ganado mucho auge desde la publicación del informe Sexismo lingüístico y visibilidad de la mujer, firmado por Ignacio Bosque (2012), aunque no de su específica autoría. Como bien señala Moreno Cabrera (2012), se trata de un documento corporativo que según se detalla al final de este, lo suscriben 26 numerarios (tres mujeres y 23 hombres) más siete miembros correspondientes (dos mujeres y cinco hombres). Queda implícito que, desde el punto de vista institucional, el contenido también fue refrendado por la ASALE, cuyo secretario general para esa fecha (Humberto López Morales) aparece como firmante del texto. En consecuencia, la posición oficial de la RAE y de la ASALE es muy clara y se ajusta sin cortapisas al contenido de la NGLE:

Hay acuerdo general entre los lingüistas en que el uso no marcado (o uso genérico) del masculino para designar los dos sexos está firmemente asentado en el sistema gramatical español, como lo está en el de otras muchas lenguas románicas y no románicas, y también en que no hay razón para censurarlo (Bosque, 2012, p. 6) ${ }^{13}$.

Más aún, en artículos de opinión, declaraciones a la prensa y entrevistas posteriores, algunos académicos españoles y americanos no solo reafirman directa o indirectamente el contenido del informe, sino que además lo refuerzan con argumentos adicionales (ver, por ejemplo, Álvarez de Miranda, 2012; Gutiérrez Ordóñez, 2018; Moure, 2018). Lo mismo hacen escritores, lingüistas y comunicadores sociales (EscandellVidal, 2018; Grijelmo, 2018; Montero, 2012; Sarlo, 2018). No obstante, como es natural y ante un tema abiertamente polémico, aparecen voces, si no completamente disidentes de la opinión académica, al menos más abiertas frente al tema del masculino inclusivo (Márquez Guerrero, 2016; Rojas, 2017).

La Tabla 3 recoge algunas de dichas opiniones, expresadas públicamente, antes y después de la publicación del documento de la RAE-ASALE. En la misma, se hace evidente que los juicios más radicales,

13 Esta posición se ratifica en el Libro de estilo de la lengua española. Según la norma panhispánica (RAE-ASALE, 2018). 
aquellos que no ofrecen ninguna posibilidad para un cambio que haga desaparecer grafemática y morfológicamente la invisibilidad de lo femenino, son precisamente los de los numerarios de la RAE (Álvarez de Miranda, 2012; Fernández Ordóñez, 2011; Gutiérrez Ordóñez, 2018).

Tabla 3. Opiniones diversas sobre el masculino inclusivo (hablantes públicos).

\begin{tabular}{|c|c|}
\hline $\begin{array}{l}\text { Araceli López Serena } \\
\text { (2011), lingüista }\end{array}$ & $\begin{array}{l}\text { "Las críticas que se suelen hacer al injustamente denostado } \\
\text { masculino genérico - o empleo del masculino como género } \\
\text { gramatical no marcado (que no neutro) - resultan mucho } \\
\text { menos acertadas". }\end{array}$ \\
\hline $\begin{array}{l}\text { Inés Fernández Ordóñez } \\
\text { (2011), filóloga, numeraria } \\
\text { de la RAE. }\end{array}$ & $\begin{array}{l}\text { "Es inapropiado pretender solucionar problemas sociales por } \\
\text { la vía del lenguaje. (...) Es como cuando dicen que las mujeres } \\
\text { son invisibles porque el plural se hace en masculino". }\end{array}$ \\
\hline $\begin{array}{l}\text { Pedro Álvarez de Miranda } \\
\text { (2012), lexicógrafo, nume- } \\
\text { rario de la RAE. }\end{array}$ & $\begin{array}{l}\text { "Intentar revertirlo o anularlo es darse de cabezadas contra } \\
\text { una pared, porque la cosa, en verdad, no tiene remedio (...) } \\
\text { una terca realidad contra la que es estéril estrellarse: la condi- } \\
\text { ción inamovible del masculino como género no marcado". }\end{array}$ \\
\hline $\begin{array}{l}\text { Salvador Gutiérrez } \\
\text { Ordóñez (2012), gramático } \\
\text { y numerario de la RAE, } \\
\text { citado por Prieto (2018). }\end{array}$ & $\begin{array}{l}\text { "Lo que no se puede es atentar contra el sistema mismo de } \\
\text { nuestra lengua. Y el masculino genérico, el uso neutro, perte- } \\
\text { nece a ese sistema". }\end{array}$ \\
\hline $\begin{array}{l}\text { Rosa Montero (2012), } \\
\text { escritora. }\end{array}$ & $\begin{array}{l}\text { "Quizá en el futuro la concordancia se hará con el género que } \\
\text { más abunde en cada momento". }\end{array}$ \\
\hline $\begin{array}{l}\text { María Márquez Guerrero } \\
\text { (2016), lingüista. }\end{array}$ & $\begin{array}{l}\text { "El masculino genérico se presenta como insuficiente e impre- } \\
\text { ciso, ya que no solo no designa con transparencia la realidad, } \\
\text { sino que incluso nos impide percibir o imaginar cambios". }\end{array}$ \\
\hline $\begin{array}{l}\text { Darío Rojas (2017), lingüis- } \\
\text { ta, miembro correspon- } \\
\text { diente de la Academia } \\
\text { Chilena de la Lengua. }\end{array}$ & $\begin{array}{l}\text { “No son en absoluto aberraciones, no tienen nada de malo } \\
\text { en sí y no 'atentan' contra la lengua como a veces se dice. Las } \\
\text { variantes van y vienen, siempre van surgiendo novedades en } \\
\text { las lenguas, algunas permanecen y otras pasan”. }\end{array}$ \\
\hline $\begin{array}{l}\text { José Luis Moure (2018), } \\
\text { filólogo, numerario de la } \\
\text { Academia Argentina de } \\
\text { Letras. }\end{array}$ & $\begin{array}{l}\text { "Cabe preguntarse si la mayor parte de los hablantes nece- } \\
\text { sitará afectar la economía de su expresión recurriendo a ese } \\
\text { mecanismo de redundancia, pero se trata de una elección } \\
\text { cuya aceptación y generalización es impredecible". }\end{array}$ \\
\hline $\begin{array}{l}\text { Beatriz Sarlo (2018), perio- } \\
\text { dista y ensayista. }\end{array}$ & $\begin{array}{l}\text { "Sorprende la confianza con que hoy se quiere implantar el } \\
\text { uso conjunto de masculino y femenino, como si esa transfor- } \\
\text { mación lingüística garantizara una igualdad de género". }\end{array}$ \\
\hline $\begin{array}{l}\text { Álex Grijelmo (2018), } \\
\text { periodista y escritor. }\end{array}$ & $\begin{array}{l}\text { "Cuando la realidad cambie, el contexto alterará el significado } \\
\text { de las palabras sin necesidad de alterar su significante". }\end{array}$ \\
\hline $\begin{array}{l}\text { Victoria Escandell-Vidal } \\
\text { (2018), lingüista. }\end{array}$ & $\begin{array}{l}\text { "La evolución de las lenguas nos ofrece ejemplos muy inte- } \\
\text { resantes sobre cómo las realidades sociales promueven de } \\
\text { manera espontánea cambios promovidos desde la conciencia } \\
\text { lingüística de la colectividad de usuarios: cambios parciales, } \\
\text { paulatinos, y siempre dentro de las posibilidades del sistema, } \\
\text { sin subvertir sus fundamentos". }\end{array}$ \\
\hline
\end{tabular}

Fuente: Elaboración propia, a partir de datos compilados de la prensa y páginas electrónicas. 
No obstante, no se trata solamente de una posición casi de militancia dentro de la RAE. Obsérvese la misma vehemencia en los juicios de la lingüista López Serena (2011) y la ensayista Beatriz Sarlo (2018). Desde puntos de vista más o menos similares, otros no dejan de lado la factibilidad de algunos futuros cambios, siempre que estos no incidan en alteraciones del sistema (Grijelmo, 2018; Escandell-Vidal, 2018). Pero tampoco faltan quienes prefieren ver el tema desde una perspectiva ubicada en la posibilidad de que alguna modificación podría ocurrir si eventualmente cambiase la realidad (Montero, 2012; Moure, 2018; Rojas, 2017).

De todas las opiniones recogidas, la única que plantea abiertamente la invisibilidad de la mujer propiciada por el masculino inclusivo es Márquez Guerrero (2016): sin eufemismos, recurre al mismo tópico de la relación entre realidad y lenguaje, pero ya abiertamente a favor de una posibilidad que solvente el problema.

Ahora bien, independientemente de la inamovilidad y/o blindaje supuestamente inexpugnable del sistema (principalmente en cuanto al componente morfológico), conviven actualmente diversas propuestas que buscan remover lo que - según la opinión de algunos de esos hablantes públicos - parece inmodificable. Se ofrece un resumen de doce de ellas en la Tabla 4, las cuales hemos podido documentar hasta ahora, aunque si alguna(s) resultará(n) definitivamente exitosa(s) o no, solo se sabrá en un futuro.

En cuanto a las oposiciones léxicas alusivas a las profesiones (Tabla 4, alternativa 1), es obvio que poco a poco han venido ganando terreno. La inicial resistencia de algunos hablantes a delimitar debidamente los oficios y profesiones desempeñados por mujeres se hace cada día más débil, apoyada principalmente por la aceptación académica que, desde hace bastante tiempo, ha venido incorporando muchas de ellas al DLE (jueza, presidenta, médica, fiscala, congreganta, ministra, sicóloga, bedela, gerenta, árbitra, aprendiza, capitana, torera, capataza, cacica, parienta, prójima, individua, intendenta, concejala, etc. ${ }^{14}$ ) y se espera

\footnotetext{
14 En la renuencia de algunas mujeres para aludir a ciertas profesiones en femenino (médica, psicóloga, jueza, regenta, ginecóloga, ingeniera, gerenta, música, física, crítica, torera, odontóloga, etc.) sobrevive el prejuicio de que antiguamente algunos usos de esta naturaleza aludían a la "mujer del...", principalmente cuando los hombres ocupaban cargos de tipo administrativo-gubernamental (presidente, juez, alcalde, regente, comendador, gerente, etc.). Tanto es así que esta orientación sobrevive todavía en algunas acepciones del DLE, aunque con marca de desusadas. Véase, por ejemplo,
} 
que en un futuro el uso consagre otras $\left({ }^{*}\right.$ soldada, *generala, *sargenta, *corresponsala, *gasfitera, *jequesa, *cancillera, * mariscala, etc., pero no bajo la acepción "mujer de", sino como propias del desempeño femenino). Con algunas de esas voces existe cierta reserva académica en cuanto a su adecuación que solo el tiempo determinará si es o no válida; por ejemplo, casos como * miembra y *cónsula (en lugar de su equivalente, consulesa, de uso bastante restringido, con índice de cero frecuencia en los distintos corpus de la RAE (CREA, CORDE y CORPES $\mathrm{XXI}$ ); caso parecido al de chofera, en lugar de la que sí registra el $D L E$, choferesa), pero es obvio que se trata de una corriente que cada día se fortalece más en respuesta a la incorporación de la mujer a los múltiples oficios de la sociedad actual ${ }^{15}$.

En cuanto a las opciones morfosintagmáticas (casos 2, 3, 4, 5) y la de los sustantivos colectivos (caso 7), el hecho de que ya diversas páginas institucionales (gobiernos, universidades y corporaciones) hayan puesto en práctica algunos de estos recursos de sustitución del masculino inclusivo permite suponer que el cambio ha comenzado a operar, aunque faltaría que se filtre hacia otros niveles diafásicos y diastráticos para que, una vez que logren consenso social, el uso los imponga (o los deseche, si fuera el caso). La alternativa 5, que sepamos, no ha tenido hasta ahora ninguna repercusión, quizás porque no soluciona realmente el problema; por el contrario, lo mantiene, debido a que continuaría siendo excluyente (ahora de lo masculino). No se trata de que el término inclusivo aclare que la mayoría de los integrantes de un grupo pertenece a uno u otro género, sino de que, precisamente, muestre un nivel de neutralidad que no obvie a ninguno o los incluya (a todos). Por otra parte, igual que el resto de las propuestas, implícitamente se asume que la condición genérica sigue siendo binaria. En tal caso excluiría, por ejemplo, a quienes se identifican como parte de un "tercer o cuarto género" (Bergero et al., 2008). Sin olvidar que, en casos en que no haya presencia física de los referentes o se trate de multitudes, para poder emitir el enunciado el hablante tendría que adivinar si su alocución aludirá a una mayoría de hombres o de mujeres.

la acepción 7 de la definición de presidente: “f. coloq. Mujer del presidente”. Lo mismo vale para muchos otros ejemplos (alcaldesa, jueza, intendenta, regenta, etc.).

15 Interesantes y muy documentadas reflexiones en torno a la factibilidad de miembra aparecen en Vigara Tauste (2008). 
Tabla 4. Algunas de las propuestas para sustituir el masculino inclusivo.

\begin{tabular}{|c|c|}
\hline Marca de género & Ejemplo(s) \\
\hline $\begin{array}{l}\text { 1. Oposición léxica surgida por los } \\
\text { cambios de rol de la mujer (normali- } \\
\text { zados o *en proceso de uso). }\end{array}$ & $\begin{array}{l}\text { Juez/jueza, médico/médica, fis- } \\
\text { cal/fiscala, general/*generala, } \\
\text { miembro/*miembra, corresponsal } \\
/{ }^{*} \text { corresponsala, portavoz/*portavoza. }\end{array}$ \\
\hline 2. Desdoblamiento léxico. & $\begin{array}{l}\text { Diputadas y diputados, presidente o } \\
\text { presidenta. }\end{array}$ \\
\hline $\begin{array}{l}\text { 3. Coordinación de determinantes y } \\
\text { nombres. }\end{array}$ & Los y las niños y niñas. \\
\hline $\begin{array}{l}\text { 4. Barra oblicua (/) entre determinan- } \\
\text { tes para marcar la diferencia. }\end{array}$ & $\begin{array}{l}\text { El/la niño/a. } \\
\text { Los/las niños/as. }\end{array}$ \\
\hline $\begin{array}{l}\text { 5. Diferenciación de género mediante } \\
\text { uso de paréntesis en pronombres y/o } \\
\text { adjetivos. }\end{array}$ & $\begin{array}{l}\text { Lectores y lectoras motivados(as). } \\
\text { Ellos(as) mismos(as). }\end{array}$ \\
\hline $\begin{array}{l}\text { 6. Uso del femenino genérico como } \\
\text { sustituto del masculino. }\end{array}$ & $\begin{array}{l}\text { Todas las profesoras/niñas/diputadas/ } \\
\text { ministras. } \\
\text { Consejo de ministras }\end{array}$ \\
\hline $\begin{array}{l}\text { 7. Uso de sustantivos colectivos como } \\
\text { garantía de inclusión. }\end{array}$ & $\begin{array}{l}\text { La ciudadanía, la humanidad, el estu- } \\
\text { diantado, profesorado. }\end{array}$ \\
\hline $\begin{array}{l}\text { 8. Asterisco como marca de género } \\
\text { inclusivo "neutro" }\end{array}$ & $\begin{array}{l}L^{*} s \text { niñ }{ }^{*} s \text { salieron de paseo con sus } \\
\text { docent*s. }\end{array}$ \\
\hline $\begin{array}{l}\text { 9. Signo de 'igual' (=) como marca de } \\
\text { género inclusivo "neutro". }\end{array}$ & " $\mathrm{L}=\mathbf{s}$ trabajador $=\mathbf{s}$ aquí reunid $=\mathbf{s}$ ". \\
\hline $\begin{array}{l}\text { 10. Uso de una X como marca de géne- } \\
\text { ro inclusivo "neutro". }\end{array}$ & $\begin{array}{l}\text { “iLibertad a todxs lxs presxs políticxs } \\
\text { chilenxs y mapuches!”. }\end{array}$ \\
\hline $\begin{array}{l}\text { 11. Uso de la @ como marca de género } \\
\text { inclusivo "neutro". }\end{array}$ & $\begin{array}{l}\text { "1@s rebeldes que se encuentran } \\
\text { sol@s" (Cuba, 2016). }\end{array}$ \\
\hline $\begin{array}{l}\text { 12. Uso de la 'e' como marca de género } \\
\text { inclusivo "neutro". }\end{array}$ & "Les compañeres anarquistes". \\
\hline
\end{tabular}

Fuente: Elaboración propia a partir de datos compilados en parte de la documentación consultada.

Las propuestas $8,9,10,11$ y 12 tienen en común el hecho de requerir la inserción de un componente morfológico que implique a ambos géneros $-\mathrm{o}$ a todos-, si se trata de romper el binarismo. Algunas de ellas, además, presentan el problema de no ser parte del sistema grafemático del español (el asterisco ‘*', la arroba '@’ y el signo de igual '=', por ejemplo); aparte de que solo solventarían el problema en la 
lengua escrita ${ }^{16}$. En cuanto a la inserción de una ' $x$ ', que sí es parte de los sistemas alfabético y fonético, surgiría el inconveniente ya mencionado por algunos en cuanto a la dificultad para pronunciarlo (Cuba, 2017). De acuerdo con la Ortografía básica de la lengua española (RAE, 2012), la pronunciación americana de la letra $<\mathrm{x}>$ en posición intervocálica $\mathrm{o}$ en final de sílaba corresponde a la secuencia fonética $[k+s]$. De adoptarse esta opción, el resultado iría contra las reglas fonetológicas del español. Omitiendo detalles fonéticos no pertinentes aquí, retomemos el ejemplo de la Tabla 4 (opción 10):

¡Libertad a todxs lxs presxs políticxs chilenxs y mapuches!

[libertad a todkss lkss preskss polítikkss chilenkss y mapuches]

Aunque igualmente pareciera poco natural (y quizás pueda ser tildada de artificiosa), la única posibilidad de que este tipo de alternativas (propuestas 8, 9, 10, 11 y 12) tuviera éxito alguna vez dependería de la incorporación de una 'e' como morfema neutro (inclusivo de masculino, femenino y otros, sin diferenciación morfológica de ningune), en los casos en que ello sea posible. Aceptemos que incluso pudiera competir (o convivir) con las opciones léxicas 1, 2 y 7 , y con las morfosintagmáticas (propuestas 3, 4 y 5). Entre las morfológicas, esta resulta hasta ahora la que ofrece menos dificultades ${ }^{17}$, pero objetivamente hace falta mencionar algunos de sus pros y sus contras.

Lo primero que puede plantearse es que, si sobreviven en español algunas trazas de lo que fue el neutro en latín (lo, ello, esto, eso, aquello), ¿por qué cerrarse a la posibilidad de ampliar el espectro que tenemos hasta ahora (limitado a unas pocas categorías)? Si el neutro estuvo en el origen y permanece en la memoria semántica remota de los hablantes de español, habría la posibilidad de darle cabida de nuevo, mediante el surgimiento de un morfema que no se parcialice por ninguno de los dos géneros gramaticales y los atienda a todos.

\footnotetext{
16 Véase lo que dice el Diccionario panhispánico de dudas (en línea) respecto de la @: “Debe tenerse en cuenta que la arroba no es un signo lingüístico y, por ello, su uso en estos casos es inadmisible desde el punto de vista normativo; a esto se añade la imposibilidad de aplicar esta fórmula integradora en muchos casos sin dar lugar a graves inconsistencias, como ocurre en Día del niñ@, donde la contracción del solo es válida para el masculino niño".

17 Según reporte y cita de Sarmiento Salinas (2015), la propuesta es de vieja data. Alude a un artículo de Álvaro García Meseguer, del año 1976: "Sexismo y lenguaje”. Cambio, 16, 260). El mismo Sarmiento Salinas hace uso de la inserción de la 'e' como marca de neutralidad durante el desarrollo de su ponencia.
} 
En segundo lugar, el principio general de economía se mantendría incólume (Sarmiento Salinas, 2015), solo implicaría expandir las posibilidades del subsistema morfológico. ¿Imposible? No lo sabremos hasta que se ponga en práctica y su uso comience a generalizarse: si como sabemos el uso consagra, ya han comenzado a percibirse algunos intentos aislados ${ }^{18}$, como los que pueden verse en los trabajos de Acosta (2016) y Cuba (2017) y en los testimonios de la aparición de este recurso y otros de los incluidos en la Tabla 4. Además, la 'e' podría servir igualmente para la oralidad y la escritura.

En tercer lugar, el español actual contiene algunos vocablos en los que ya la vocal 'e' no resultaría extraña como marca inclusiva referida a personas (bebé, intérprete, hablante, confiable, negligente, congénere, informante, estudiante, amable, etc.). Y, finalmente, habría que señalar que quienes propician su uso como marca de LI, a lo mejor sin darse cuenta han acudido a un elemento que tiene lo que pudiera denominarse validez ecológica, por cuanto ya forma parte de un sistema grafemático y fonológico establecidos y su nueva función no causaría ningún tipo de desequilibrio sistémico dentro del mismo (como sí ocurriría con otras propuestas similares: '*’ , ‘@’ ' '=‘ y 'x', por ejemplo). Además, dentro de nuestro sistema vocálico, la 'e' resulta bastante neutra desde el punto de vista articulatorio (palatal media).

Sin embargo, no todo es tan nítido como lo hemos expuesto en los párrafos anteriores. Por ejemplo, ¿cuán natural pudiera resultar que digamos "Muches de les preses polítices chilenes son unes chiquilles?", en lugar de "Muchos de los presos políticos chilenos son unos chiquillos",

\footnotetext{
18 Ver, por ejemplo, el artículo de opinión “Paola Francia responde al artículo de su padre: Néstor Francia: Argentina; Aborto abortado". Disponible en http://www.costadelsolfm.net/2018/08/13/paolafrancia-responde-al-articulo-de-su-padre-nestor-francia-argentina-aborto-abortado/ En el mismo se utilizan términos como compañeres, niñes, huérfanes, todes, entre otros. También la expresión nosotres aparece en unas declaraciones de Caterine Galaz (académica de Trabajo Social en la Universidad de Chile) en entrevista de Sepúlveda Garrido (2018). En la misma, Michele Riquelme se identifica como Coordinadore Ejecutive de la OTD (Organizando Trans Diversidades) de Chile y en sus declaraciones utiliza además todes. Adicionalmente, en la diversa documentación de la página virtual de la OTD (https://otdchile.org/), es regular la utilización de la 'e' como marca que no alude ni a masculino ni a femenino. El mismo trabajo periodístico de Sepúlveda Garrido (2018) incluye declaraciones bastante ponderadas sobre este tema del (para ese momento) director de la Academia Chilena de la Lengua, Alfredo Matus Olivier: "los cambios en la educación, el movimiento feminista, por ejemplo, tienen mucha fuerza, y están marcando una especie de dirección de la sociedad hacia nuevos horizontes" (p. 1). Valga destacar también el tono supuestamente humorístico del titular del trabajo periodístico, publicado en el diario La Tercera por Sepúlveda Garrido (2018): desde la perspectiva del análisis crítico del discurso, dicho titular pudiera reflejar una toma de posición de parte del diario, o de la redactora: Por qué la RAE le dijo nones al 'todes'.
} 
donde la inserción recurrente de la 'e' casi nos hace pensar que se trata de una lengua diferente al español, lo cual debilitaría esta alternativa. Además, ¿qué deberíamos inferir cuando leamos o escuchemos otra oración como "Les jefes de la empresa salieron de vacaciones"? El femenino actual de jefe es jefa. De aceptarse la 'e' como morfema inclusivo (jefe), coincidiría con el actual masculino (jefe) y esto podría acarrear un problema diferente: la modificación del sistema para que se produzca una tríada como *jefo/jefa/jefe (masculino, femenino, inclusivo, equivalente a preso/presa/prese y otros términos similares). En tal caso, tendrían cierta ventaja las propuestas menos lesivas para el sistema de la lengua, por ejemplo, las morfosintagmáticas (que, en mayor o menor medida, ya se utilizan tanto en la oralidad como en la escritura).

\section{Conclusiones}

En este artículo hemos intentado ofrecer los resultados iniciales de una investigación que, superando las consideraciones bastante restrictivas de la teoría lingüística y gramatical, descienda al terreno del habla y la escritura concretas, a fin de verificar qué piensan y cómo ven realmente los hablantes-escritores que no son docentes, lingüistas o académicos los temas referentes a la relación género gramatical/sexo y el masculino inclusivo en español. Investigar la realidad concreta podría revelarnos el hecho de que no parece existir conexión entre lo que propone la teoría gramatical y algunas organizaciones y lo que ocurre realmente en la conciencia lingüística del colectivo, esto es, los usuarios. Según nuestras indagaciones preliminares, hay dos convicciones de los hablantes que parecen tener realidad sicológica: 1) identidad género/sexo para referentes +animados +sexuados como un hecho que parece tener consenso social $^{19}$; y 2) convicción de que el masculino plural inclusivo es un hecho lingüístico socialmente instaurado, al menos entre profesionales universitarios no docentes, es decir, forma parte de la competencia sicosocio-

\footnotetext{
19 En cuanto a eso, ¿acaso la misma RAE contribuye a ratificar este "saber popular"? Véase el contenido del siguiente tuit, emitido por la corporación en respuesta a una consulta (19 de julio de 2018): “\#RAEconsultas El español ya dispone de un mecanismo inclusivo: el uso del masculino gramatical que, como término no marcado de la oposición de género, puede referirse a grupos formados de hombres y mujeres y, en contextos genéricos o inespecíficos, a personas de uno u otro sexo". Véase, además, la acepción 8 del actual DLE (en línea): “Gram. Categoría gramatical inherente en sustantivos y pronombres, codificada a través de la concordancia en otras clases de palabras y que en pronombres y sustantivos animados puede expresar el sexo" (subrayados añadidos).
} 
comunicativa. Una contradice en mayor o menor medida la preceptiva gramatical vigente; la otra, da la razón a los diversos hablantes públicos que han defendido y justificado esa regla ${ }^{20}$, de modo que no parece tan sencillo intentar que se modifiquen solo a partir de dictámenes intervencionistas o deseos de carácter gramatical o socioideológico. No obstante, tampoco resulta pertinente asumir posturas intolerantes que nieguen la posibilidad de un cambio futuro en esto de las reglas gramaticales y la invisibilización gramatical no solo de las integrantes del sexo femenino, sino también de otros, existentes o emergentes.

Como hemos visto, varias opciones están en la palestra pública. Algunas de ellas ya han ganado cierto auge, principalmente dentro del lenguaje administrativo de muchas instituciones; otras no han tenido tanto éxito, porque propician modificaciones que, más allá del léxico, buscan incidir en el subsistema morfológico de la lengua, lo que las complejiza, aunque no las hace definitivamente inviables ni imposibles a todas, como afirman algunos académicos. Dentro del conjunto de estas últimas, resaltan las opciones que defienden la creación de una marca de género, con distintas variantes (“*', '@’ ' '=', 'x' y 'e', entre las más conocidas). De todas, la aparentemente menos compleja podría ser la inserción de una 'e' como marca de neutralidad; lo que para nada implica que pueda tener algún éxito ni que no acarree serios retos ante la alteración del actual subsistema morfológico del español, a menos que de verdad el uso en todos los ámbitos diastráticos, diafásicos y diatópicos de la lengua (y no solamente en la escritura administrativa o de los medios) llegue a imponerse.

Percibimos, eso sí, que de parte de quienes la(s) auspician, no haya habido hasta ahora una propuesta formal que supere los límites de la militancia y se aboque a ofrecer razones lingüísticas de peso para superar lo que sigue constituyendo un ruido comunicacional innegable: es obvio que la noción del masculino inclusivo no marcado está más que cuestionada y las iniciativas para resolver dicha situación deben ser vistas con la mesura que debe existir entre quienes, como hablantes públicos, tienen la responsabilidad de atender los reclamos de los usuarios y no cerrarse de antemano. Algunos usos ya han comenzado a incidir en lo

20 Según Márquez (2013) “el masculino tiende a identificarse con la referencia 'varón', y no se debe a un error del oyente, sino a una asociación histórica general y constante en el uso” (p. 57). 
profundo (semántico) de la estructura del español y a ello debemos estar atentos.

Si queremos ser realistas, ya muchos nos hemos ido acostumbrando a la alusión expresa de masculino y femenino (por escrito y en la oralidad formal) para referirnos a hombres y mujeres, al uso de determinantes u otros recursos léxicos para establecer la diferencia. El problema con este uso es que, si bien pone a dos géneros gramaticales en condiciones de igualdad (opción binaria), a veces no se toma en cuenta que, en cuanto a la relación género/sexo, habrá quienes no se sienten ni masculinos ni femeninos (García-Granero, 2017), y las propuestas también deberían tomar esto en cuenta. En obvio, entonces, que debemos seguir investigando formalmente en torno a este tema, sin banalizarlo ni acudiendo a posiciones extremistas o a salidas humorístico-paródicas.

\section{Referencias bibliográficas}

Acosta, M. (2016). Subversiones lingüísticas del español: @, X, e como morfemas de género inclusivo y otros recursos estilísticos en publicaciones anarquistas contemporáneas (Tesis de maestría inédita). City College of New York, Nueva York, Estados Unidos.

Álvarez de Miranda, P. (7 de marzo de 2012). El género no marcado. $E l$ País. Recuperado de https://elpais.com/cultura/2012/03/07/ actualidad/1331150944 957483.html.

Barrera Linares, L. (2013). No solo cenizas hallarás. Léxico sobreviviente en el discurso del bolero hispanoamericano. Lingua Americana, 17(33), 39-66.

Bécares Botas, V. (2002). Gramática. Comentarios antiguos. Madrid: Gredos.

Bergero Miguel, T., Asiain Vierge, S., Gorneman Schaffer, I., Giraldo Ansio, F., Lara Montenegro, J., Esteva de Antonio, I., y Gómez Banovio, M. (2008). Una reflexión sobre el concepto de género alrededor de la transexualidad. Revista de la Asociación Española de Neuropsiquiatría, 28(1), 211-226. https://doi. org/10.4321/s0211-57352008000100013

Bello, A. (1847). Gramática de la lengua castellana destinada al uso de los americanos. Recuperado de https://www.biblioteca.org.ar 
Borrego Nieto, J. (Dir., 2016). Gramática de referencia para la enseñanza del español. Salamanca: Universidad de Salamanca.

Bosque, I. (2012). Sexismo lingüístico y visibilidad de la mujer. Boletín de Información Lingüística de la Real Academia Española, 1, 1-18. https://www.rae.es/sites/default/files/Sexismo linguistico y visibilidad de la mujer $0 . p d f$

Cabeza Pereiro, M. del C. y Rodríguez Barcia, S. (2013). Aspectos ideológicos, gramaticales y léxicos del sexismo lingüístico. Estudios Filológicos, 52, 7-27. https://doi.org/10.4067/ s0071-17132013000200001

Cole, M. (1999). Psicología cultural. Madrid: Morata.

Cuba, E. (2017). Agitando lo cotidiano. Una conversación sobre el desafío @narquista frente al sexismo en el lenguaje. LL Journal. Recuperado 15 de enero de 2019 de https://lljournal.commons. gc.cuny.edu/2016/12/02/cuba-v11-216/

Ecker, P. \& McConnel-Ginet, S. (2003). Language and gender. Cambridge: Cambridge University Press, CUP.

Escandell-Vidal, V. (2018). Reflexiones sobre el género como categoría gramatical. Cambio ecológico y tipología lingüística. [prepublicación]. Recuperado 27 de diciembre de 2018 de https://www.researchgate.net/publication/326583738_ REFLEXIONES SOBRE EL GENERO COMO CATEGORIA GRAMATICAL CAMBIO ECOLOGICO Y TIPOLOGIA LINGUISTICA

Fernández Ordóñez, I. (20 de febrero de 2011). Es inapropiado pretender solucionar problemas sociales por la vía del lenguaje. Entrevistada por Iker Seisdedos. El País Semanal. Recuperado de https://elpais.com/diario/2011/02/20/ eps/1298186814 850215.html

García-Granero, M. (2017). Deshacer el sexo. Más allá del binarismo varón-mujer. DILEMATA, 9(25), 253-263. Recuperado de https://www.dilemata.net/revista/index.php/dilemata/article/ view/412000146

García Meseguer, Á. (2001). ¿Es sexista la lengua española? Panace@, 2(3), 20-34. Recuperado de https://www.tremedica.org/wp-content/ uploads/n3 GarciaMeseguer.pdf 
García Mouton, P. (2012). La lengua y las edades. LYCHNOS. Cuadernos de la Fundación General CSIC, 8. Recuperado de http://www. fgcsic.es/lychnos/es es/articulos/La-lengua-y-las-edades.

Grijelmo, A. (28 de noviembre de 2018). ¿Invisibiliza nuestra lengua a la mujer? El País. Recuperado de https://elpais.com/cultura/2018/11/28/actualidad/1543418937 639835.html?utm source $=$ delcastellanocom $\& u$ tm medium $=$ email $\& u t m$ campaign=boletin_lenguas_20181208

Gutiérrez Ordóñez, S. (2018). “Lo de ‘todos y todas' es imposible de mantener". Entrevistado por Darío Prieto. El Mundo. Recuperado de https://www.elmundo.es/opinion/2018/11/03/5bdgf8ac46 163f35458b4571.html

Hernández García-Cervigón, A. (2006). El grupo del nombre en la analogía de la GRAE, 1771-1917. Madrid: Editorial Complutense.

Kozac, G. (2018). Una feminista fuera de lugar. Literal. Recuperado de http://literalmagazine.com/una-feminista-fuera-de-lugar/

Llamas Sáiz, C. (2015). Academia y hablantes frente al sexismo lingüístico: ideologías lingüísticas en la prensa española. Circula. Revue d'idéologies linguistiques, 1, 196-215. https://doi. org/10.17118/11143/7995

López Morales, H. (1988). Índices de mortandad léxica en Puerto Rico. Nueva Revista de Filología Hispánica, 36(2), 733-752. https:// doi.org/10.24201/nrfh.v36i2.697

López Serena, A. (noviembre, 2011). Usos lingüísticos sexistas y medios de comunicación. En torno al denostado masculino genérico. Trabajo presentado en II Jornadas Universitarias: sexo, género y comunicación. Sevilla, España. Recuperado de https://idus. us.es/xmlui/bitstream/handle/11441/33016/Pages\%2ofrom\%20 lamujerenelespejomediatico 2-3.pdf.

Márquez, M. (2013). Género gramatical y discurso sexista. Madrid: Síntesis.

Márquez Guerrero, M. (2016). Bases epistemológicas del debate sobre sexismo lingüístico. Arbor. Ciencia, pensamiento y cultura, 192(778), 1-15. http://dx.doi.org/10.3989/arbor.2016.778n2010

Montero, R. (27 de noviembre de 2012). Todas. El País. Recuperado de https://elpais.com/elpais/2012/03/05/ opinion/1330951227 921857.html. 
Moreno Cabrera, J. C. (2012). Acerca de la discriminación de la mujer y de los lingüistas en la sociedad. Reflexiones críticas. Recuperado de http://es.scribd.com/doc/85920261/Juan-CarlosMoreno-Cabrera-UAM-\%C2\%AB\%E2\%80\%9CAcerca-dela-discriminacion-de-la-mujer-y-de-los-linguistas-en-lasociedad\%E2\%80\%9D-Re-flexiones-criticas\%C2\%BB.

Moure, J. L. (enero, 2018). Lenguaje inclusivo. Trabajo presentado en el Congreso Internacional de Correctores de Textos en Español, Colonia del Sacramento, Uruguay. Recuperado de https://5cictecongresocorrectores.wordpress.com/2018/09/03/ lenguaje-inclusivo/

Prieto, D. (30 de noviembre de 2018). Salvador Gutiérrez Ordóñez: lo de "todos y todas" es imposible de mantener. El Mundo. Recuperado de https://www.elmundo.es/opinion/2018/11/0 3/5bd9f8ac46163f35458b4571.html.

Real Academia Española, RAE (1931). Gramática de la lengua española. Madrid: Espasa-Calpe.

Real Academia Española, RAE (1973). Esbozo de una nueva gramática de la lengua española. Madrid: Gredos.

Real Academia Española, RAE y Asociación de Academias de la Lengua Española, ASALE (2009). Nueva gramática de la lengua española. Madrid, España: Espasa-Calpe.

Real Academia Española, RAE y Asociación de Academias de la Lengua Española (2012). Nueva gramática de la lengua española. Manual. (2 ${ }^{\mathrm{a}}$ ed.) Buenos Aires, Argentina: Espasa-Calpe.

Real Academia Española y Asociación de Academias de la Lengua Española (2012). Ortografía básica de la lengua española. Manual. Madrid, España: Espasa-Calpe.

Real Academia Española y Asociación de Academias de la Lengua Española (2018). Libro de estilo de la lengua española. Según la norma panhispánica. Madrid, España: Espasa Libros S. L.

Real Academia Española: Banco de datos (CORDE) [en línea]. Corpus diacrónico del español. http://corpus.rae.es/creanet.html (Último acceso: 15 de febrero de 2019).

Real Academia Española: Banco de datos (CORPES XXI) [en línea]. Corpus del español del siglo XXI. http://corpus.rae.es/creanet. html (Último acceso: 15 de febrero de 2019). 
Real Academia Española: Banco de datos (CREA) [en línea]. Corpus de referencia del español actual. http://corpus.rae.es/creanet.html (Último acceso: 15 de febrero de 2019).

Roca, I. (2013). El género del castellano: entelequias y realidades. Español actual: Revista del Español Vivo, 99, 51-96. Recuperado de https://www.fundeu.es/wp-content/uploads/2014/11/ROCAEL-G\%C3\%89NERO-DEL-CASTELLANO.pdf.

Rodríguez Díez, B. (2005). El género: del latín al español. Los géneros del romance. León: Universidad de León.

Rojas, D. (2017, marzo). Género y lenguaje inclusivo. [Entrada en un blog]. Lengua española en Chile. Recuperado de http:// lenguaespanolachile.blogspot.com/2017/03/genero-ylenguaje-inclusivo.html.

Sarlo, B. (2018). Alumnos, alumnas y 'alumnes'. El País (suplemento Babelia). Recuperado de https://elpais.com/ cultura/2018/10/09/babelia/1539083839 285133.html

Sarmiento Salinas, M. Á. (2015). La e para la desexualización del género en beneficio de la motivación de ELE en Suecia. Revitalizando la propuesta de Álvaro García Meseguer. En Y. Morimoto, M. V. Pavón Lucero, y R. Santamaría Martínez (Eds.), La enseñanza de ELE centrada en el alumno (pp. 863-872). Madrid: Asociación para la Enseñanza del Español como Lengua Extranjera, ASELE.

Sepúlveda Garrido, P. (30 de noviembre de 2018). ¿Por qué la RAE le dijo nones al tode? La Tercera. Recuperado de https://www.latercera.com/que-pasa/noticia/ la-rae-le-dijo-nones-al-todes/425248/.

Vigara Tauste, A. M. (2008). Miembra. Especulo [sección El cajetín de la lengua]. Recuperado de https://webs.ucm.es/info/especulo/ cajetin/miembra.html 